\title{
Real Time Detection of Soil Moisture in Winter Jujube Orchard Based on NIR Spectroscopy
}

\author{
Xiaofei $\mathrm{An}^{1}$, Minzan $\mathrm{Li}^{1,{ }^{1}}$, Lihua Zheng ${ }^{1}$, Yumeng Liu ${ }^{1}$, and Yajing Zhang ${ }^{2}$ \\ ${ }^{1}$ Key Laboratory of Modern Precision Agriculture System Integration Research, China \\ Agricultural University, Ministry of Education, Beijing 100083, China \\ ${ }^{2}$ Editorial office of Transaction of CSAM, CAAMS, Beijing, China \\ pactecau.edu.cn
}

\begin{abstract}
The measurement and control of soil moisture are the key technologies of precision agriculture. In order to real-time detect soil moisture content faster and more accurately, a portable soil moisture sensor based on NIR spectroscopy was developed. With the sixty soil samples collected from a winter jujube orchard, a linear regression model was established. The determination coefficients of the calibration $\left(R_{\mathrm{c}}^{2}\right)$ and validation $\left(R_{\mathrm{v}}^{2}\right)$ reached 0.88 and 0.92 , respectively. The model passed $F$-test and $t$-test and showed robust. Subsequently, two spatial distribution maps of soil moisture were generated based on the data obtained by the portable soil moisture detector and the data obtained by oven drying method, respectively. Finally, the correlation between these two maps was investigated by using the software of Surfer 8.0. The zones of dry and wet soil could be distinguished easily in both maps. The results of the study showed that the developed detector was practical.
\end{abstract}

Keywords: Soil moisture, Real time detection, Soil sensor, Near infrared reflectance spectroscopy.

\section{Introduction}

Soil moisture content is one of the most critical soil components to plant growth and land management, especially in dryland [1]. It is usually measured by the oven drying method with a quite high precision. On the other hand, the oven drying method is a difficult, costly and time consuming procedure, so that it is necessary to develop a real time soil moisture detector for the precision agriculture practice.

The near-infrared (NIR) reflectance spectroscopy is a promising non-contact measurement method available to provide rapid information about some soil physical and chemical properties, such as soil organic matter content, soil total nitrogen, potassium, phosphorous, $\mathrm{pH}$, soil moisture and particle size et al. When understanding the interaction between the NIR incident light and the soil properties, those physical and chemical parameters can be estimated based on Chemometrics.

\footnotetext{
* Corresponding author. 
Many scholars such as Shibusawa, Christy, Xiao W [2-19] have researched on estimation of soil moisture based on NIR spectroscopy in recent years. Mouazen [2] established a soil moisture forecasting model with correlation coefficient of 0.982 in the laboratory. The model method was partial least squares regression (PLSR) with $306.5 \sim 1710.9 \mathrm{~nm}$. But in the field measurement, the correlation coefficient was just 0.75 and the maximum error of measurement was above $2.5 \%$. Hummel[3] analyzed relationship between soil moisture and near infrared spectroscopy, and a model was established by the multiple linear regression (MLR) method. Peng Y.K. [4] adopted the NIR spectra (Neotec51A) to forecast soil moisture, organic matter and total nitrogen of Loess Plateau and also obtained several estimations models. Shibusawa et al. reported a development of a real-time NIR spectroscopy measurement system for soil moisture[8]. The light illumination and reflection fibre were attached to a spectrophotometer with300 -1700 nm VIS and NIR light source.

Most of above researches established forecasting models in the laboratory conditions, and the real-time detection of soil moisture has not been realized with higher practical applicability. Thus, we decided to develop a portable and reliable soil moisture sensor for the real-time management. A comparison between thematic maps of soil moisture obtained by the developed detector and oven drying method respectively was conducted. And the field experiments were executed in a winter jujube orchard to test the performance of the detector.

\section{Materials and Methods}

The winter jujube orchard was located at Beijing suburb, with the area of $1000 \mathrm{~m}^{2}$. Cultivated variety was Zhanhua winter jujube planted as south-north row direction. The range of experiment zone was E116.15268541 $\sim 116.15269492^{\circ}$ and $\mathrm{N}$ $40.030982^{\circ} \sim 40.031201^{\circ}$. The soil texture was typical loam in north China.

The detector was designed with an optical unit and a control unit. Fig.1 shows the overall structure of the soil moisture detector, and Fig. 2 shows the prototype of the detector. The optical unit included a near infrared lamp-house at $1450 \mathrm{~nm}$, a shared lamp-house drive circuit, a Y-type optical fiber shared by incidence and reflectance, a probe and an InGaAs photoelectric sensor. The control unit included an amplifier circuit, a filter circuit, an A/D circuit, a LCD display circuit and a storage circuit with U-disk. Light from near infrared lamp-house was adopted in the detector instead of the sunlight.

When the detector worked, it was pushed into soil under the surface of $30 \mathrm{~cm}$ firstly. Then the optical signal at single wavelength was transferred from the $1450 \mathrm{~nm}$ near-infrared lamp-house to the surface of the target soil via the incidence optical fiber. The reflected light from the soil surface was acquired and transferred to the InGaAs photoelectric sensor, where the optical signal was converted to the electrical signal. Subsequently, the obtained electrical signal was processed and stored temporarily by an 89S52 MCU. Finally, the calculated soil moisture content was displayed on a LCD and stored in a U-disk at the same time. 


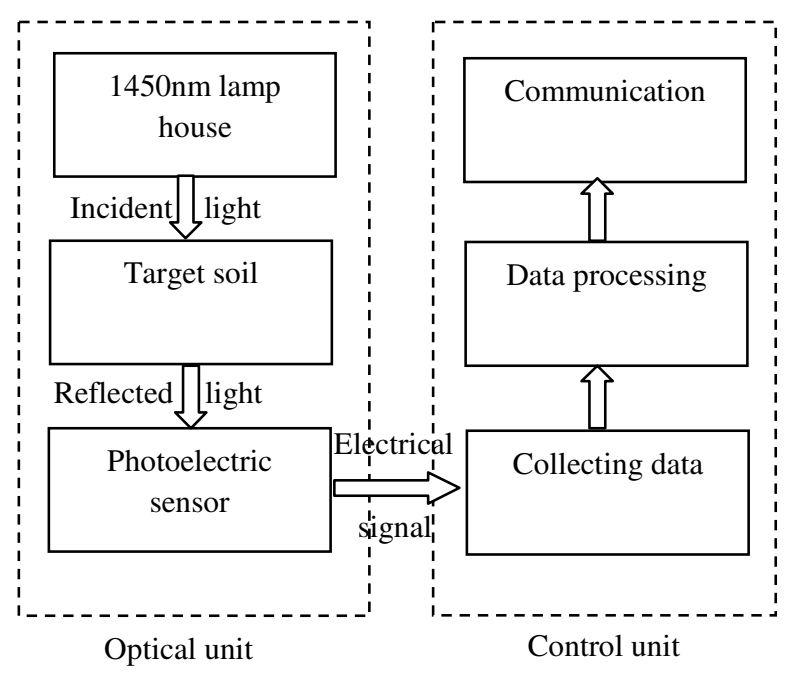

Fig. 1. Overall structure

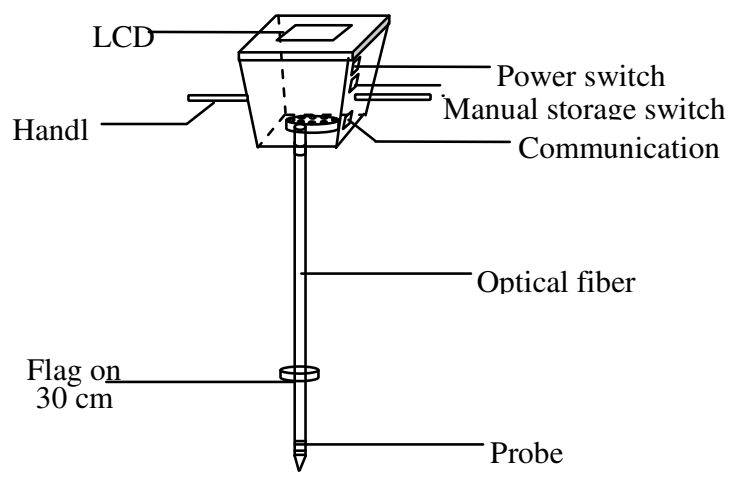

Fig. 2. Prototype of the detector

Fig. 3 shows the signal processing flow in the control unit. After the I-U converting circuit, the optical signal $\mathrm{I}_{0}$ was converted to the electrical signal $\mathrm{U}_{0}$ by the photoelectric sensor. The electrical signal $\mathrm{U}_{0}$ was a weak signal. It was necessary to design an amplifier circuit and a filter circuit before A/D circuit.

The processed signal $\mathrm{U}_{3}$ was transmitted to the MCU 89 S52. In the MCU 89S52, the data were displayed with LCD and at the same time stored in the U disk. And finally the data could also be transmitted to the PC by a serial port. 


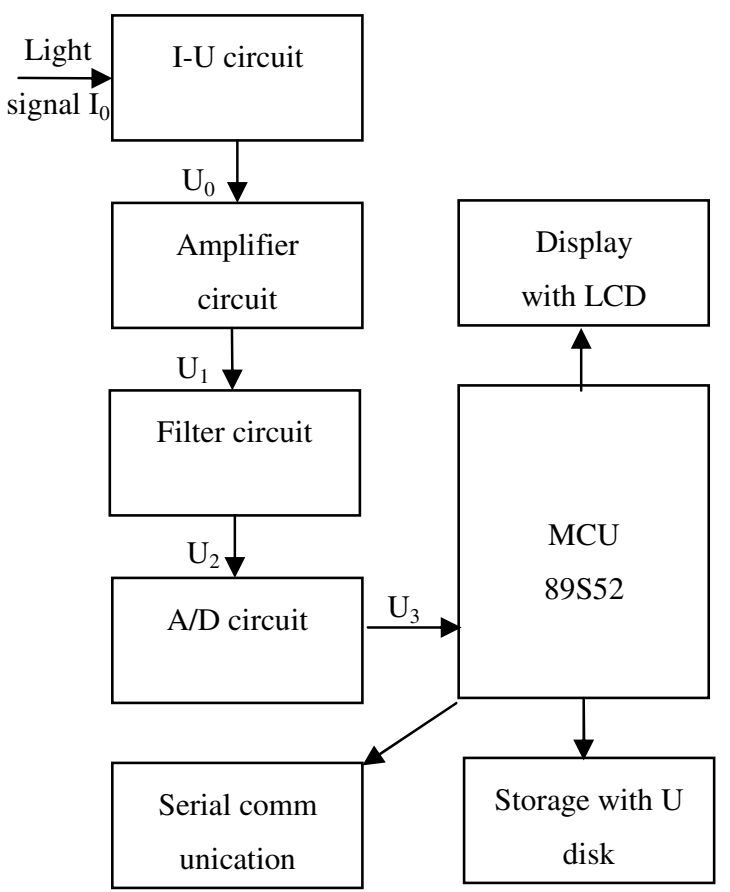

Fig. 3. Signal processing flow

In this detector several modules were included in the software, main program, subroutine of A/D conversion, subroutine of data processing, subroutine of LCD display and subroutine of storage. Fig. 4 shows the flow chart of the main program.

Absorbance was selected as the spectral parameter. In order to get the absorbance of soil samples, a standard whiteboard was designed. First, the probe of the developed soil moisture detector was put on the standard whiteboard and the output voltage $V_{i}$ of the instrument was measured. And then the probe was pushed into soil sample and the output voltage $V_{i}$ of the instrument was measured. According to the Equation (1), (2) and (3), the reflectance $r_{i}$, absorbance $A_{i}$ and average absorbance $A_{i \text { avg }}$ of every soil sample were calculated.

$$
\begin{gathered}
r_{i}=V_{i}^{\prime} / V_{i} \times 100 \% \\
A_{i}=\lg \left(1 / r_{i}\right) \\
A_{i \mathrm{avg}}=\sum_{n=1}^{6} A_{i} / 6
\end{gathered}
$$




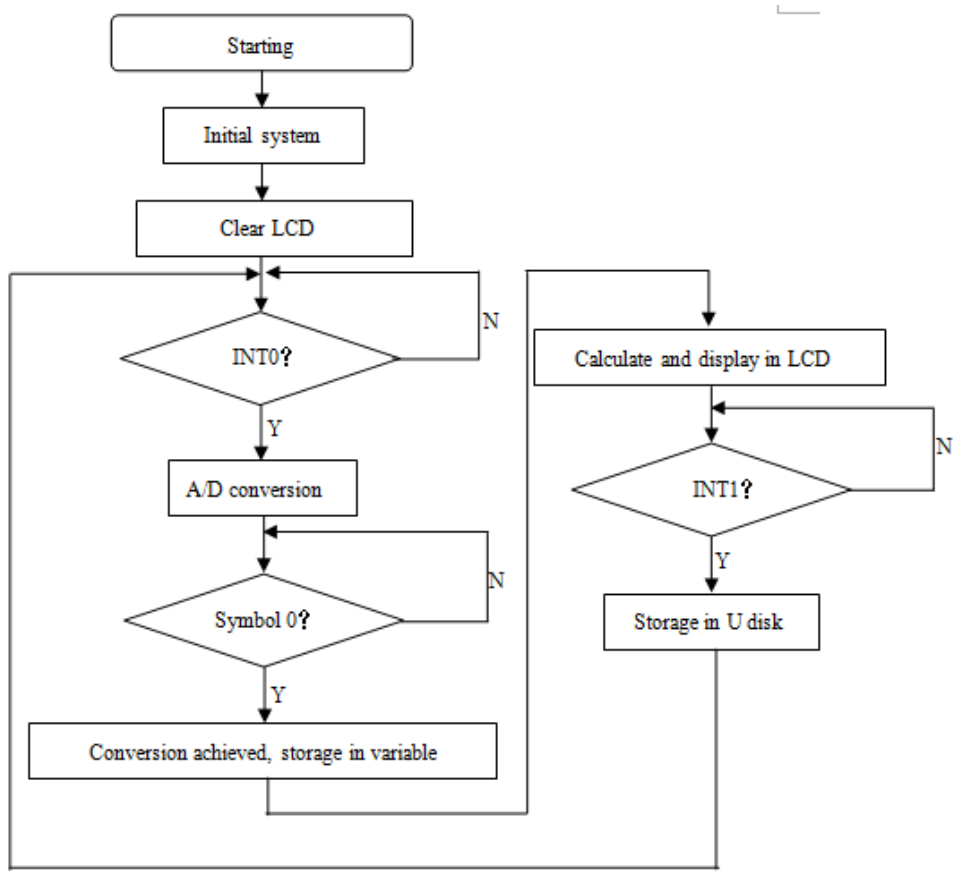

Fig. 4. Flow chart of main program

\section{Results and Discussion}

\subsection{Data Preprocessing}

Soil moisture contents of all soil samples were also measured by the oven drying method in the laboratory condition. Soil samples were subjected to oven drying at $60^{\circ} \mathrm{C}$ for 24 hours, and soil moisture content was obtained through the Equation (4).

$$
w=\frac{m_{1}-m_{0}}{m_{0}} \times 100 \%
$$

where: $w$ is soil moisture content, $m_{1}$ is original soil weight, $m_{0}$ is soil weight after oven drying.

Statistic characteristics of soil moisture contents in the winter jujube orchard are shown in Table 1. All soil samples were divided into two groups: calibration group (including 40 soil samples) and validation group (including 20 soil samples). In the calibration group, the selected soil moisture range of 3.15\% 14.19\% covered the most acquired plant and organic activities during the winter jujube season. In the validation group, the range was $4.54 \% \sim 12.09 \%$, and the average was $8.03 \%$ and the standard deviation was $2.09 \%$. 
Table 1. Statistics of soil samples

\begin{tabular}{|c|c|c|c|c|c|c|}
\hline \multirow{2}{*}{ Parameter } & \multicolumn{3}{|c|}{ Calibration group (40) } & \multicolumn{3}{|c|}{ Validation group $(20)$} \\
\hline & Range & Average & $\begin{array}{r}\text { Standard } \\
\text { deviation } \\
\end{array}$ & Range & Average & $\begin{array}{l}\text { Standard } \\
\text { deviation }\end{array}$ \\
\hline $\begin{array}{c}\text { Soil moisture } \\
(\%)\end{array}$ & $3.15 \sim 14.19$ & 8.79 & 2.41 & $4.54 \sim 12.09$ & 8.03 & 2.09 \\
\hline
\end{tabular}

\subsection{Estimation Modeling of Soil Moisture}

The object of this task was to build a statistical model between the absorbance of $1450 \mathrm{~nm}$ and soil moisture content. There were several statistical modeling techniques for the proper calibration performance, such as the linear and non-linear multiple regression analyses and the principal component analysis (PCA).

In this work, the forecasting model of soil moisture content was established by the linear regression method with the average absorbance spectral data. Fig.5 shows the comparison between measured data and predicted data of soil moisture. The forecasting model is shown in Equation (5). The determination coefficient of the calibration $\left(R_{\mathrm{c}}^{2}\right)$ was 0.88 , and the determination coefficient of the validation $\left(R_{\mathrm{v}}^{2}\right)$ was 0.92 . The model passed the F-test and t-test, which illustrated that both the model and the parameters were significant.

$$
y=35.74 \times x_{1450}-35.37
$$

where: $y$ represents the dependent variable of soil moisture content; $x_{1450}$ is average absorbance of soil at the wavelength of $1450 \mathrm{~nm}$.

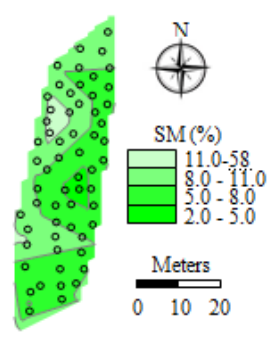

(a) Predicted SM distribution
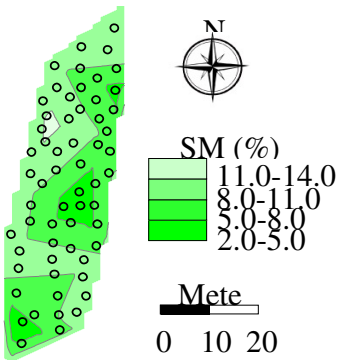

(b) Measured SM distribution

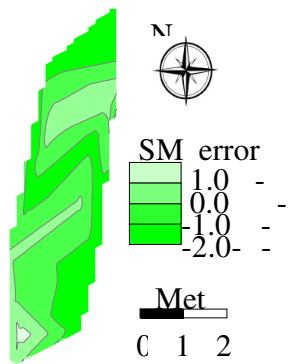

(c) SM error distribution

Fig. 5. Thematic maps of soil moisture 


\subsection{Discussion}

Use of infrared emitting diode of $1450 \mathrm{~nm}$ could make it possible to increase the frequency of sampling at a faster rate. It would also make the unit run on low power, compact and light, so that it would require little space and mechanical support.

Soil moisture content could be obtained by the soil moisture sensor. A linear regression model could satisfy the basic needs. The determination coefficient of the calibration $\left(R_{\mathrm{c}}^{2}\right)$ and validation $\left(R_{\mathrm{v}}^{2}\right)$ were 0.88 and 0.92 respectively. Root mean square error of calibration (RMSEC), root mean square error of prediction (RMSEP) and residual prediction deviation (RPD) were $0.94,0.85$ and 3.26 respectively. From the thematic maps of soil moisture, the zones of dry and wet soil could be distinguished easily. Both the results indicated that the sensor could meet the requirement of precision agriculture.

In order to increase the accuracy of the NIR measurement, other influencing parameters such as soil texture and density should be taken into account. Both the texture and density affected the results seriously. Extending the sensor application for all soil textures requires incorporating extra laboratory measurements of spectra taken from soil samples of another soil texture.

\section{Conclusions}

Soil moisture content is one of the most critical soil components to plant growth and land management, especially in dryland. In this paper, a rapid method to measure soil moisture was proposed. According to the result and discussion, the following conclusions could be obtained.

(1) A portable soil moisture detector was developed based on NIR spectroscopy. In the detector, LED of $1450 \mathrm{~nm}, Y$-type fiber and circuits were adopted to insure the sensor stable and reliable enough. It also made the unit run on low power, compact and light so that it would require little space and mechanical support.

(2) The field experiment showed that the instrument could work stably. The established model showed that there were high correlation coefficient between average absorbance of $1450 \mathrm{~nm}$ and soil moisture content, with $R_{\mathrm{c}}^{2}$ and $R_{\mathrm{v}}^{2}$ of 0.88 , 0.92 respectively. Similar spatial patterns of soil moisture measured with the developed detector and oven drying method were observed. Both above results indicated that the detector could satisfy the basic agriculture requirements.

(3) In order to improve the accuracy of soil moisture detection, soil texture should be paid more attention in the next research step.

Acknowledgements. This study was supported by Chinese National Science and Technology Support Program (2011BAD21B01), NSFC projects (61134011, and 31071330), and 863 programs (2011AA100703, 2011AA100704). 


\section{References}

1. Shang, S.P., Wang, Y.L., Hong, A.J.: Establishment of calibration equation for soil moisture content by NIRS. Chinese Journal of Spectroscopy Laboratory 28(4), 1604-1607 (2011)

2. Mouazen, A.M., Baerdemaeker, J.D., Ramon, H.: Towards development of on-line soil moisture content sensor using a fiber-type NIR spectroscopy. Soil \& Tillage Research 80(1), 171-183 (2005)

3. Hummel, J.W., Sudduth, K.A., Hollinger, S.E.: Soil moisture and organic matter prediction of surface and subsurface soils using an NIR soil sensor. Computers and Electronics in Agriculture 32(2), 149-165 (2001)

4. Peng, Y.K., Zhang, J.X., He, X.S.: Analysis of soil moisture organic matter and total nitrogen content in loess in china with near infrared spectroscopy. Acta Pedologica Sinica 35(4), 553-559 (1998)

5. Christy, C.D.: Real-time measurement of soil attributes using on-the-go near infrared reflectance spectroscopy. Computer and Electronics in Agriculture 61, 10-19 (2008)

6. Gashaw, A., Shane, M.W.: Development of a prototype infrared reflectance moisture meter for milled peat. Computer and Electronics in Agriculture 28, 1-14 (2000)

7. Xiao, W., Li, X.Y., Li, P.W.: Adaptability of the model for soil moisture measurement based on near-infrared spectroscopy. Transactions of the Chinese Society of Agricultural Engineering 25(3), 33-36 (2009)

8. Shibusawa, S., Made, I., Anom, S.W.: Site-specific crop response to temporal trend of soil variability determined by the real-time soil spectrophotometer. In: Proceedings of the Joint European Conference of ECPA-ECPLE, pp. 639-643. Wageningen Academic Publishers, Berlin (2003)

9. Liang, X.Y., Li, X.Y., Lei, T.W.: Study of sample temperature compensation in the measurement of soil moisture content. Measurement 44(10), 2200-2204 (2011)

10. Liang, X.Y., Li, X.Y., Wang, W.: NIR Spectroscopy Based on DWT and LS-SVM for Prediction of Soil Moisture. In: Proceedings of the 2010 International Conference on Electrical and Control Engineering (ICECE 2010), pp. 5874-5876 (2010)

11. Minasny, R., Alex, B.M., Veronique, B.M.: Removing the effect of soil moisture from NIR diffuse reflectance spectra for the prediction of soil organic carbon. Geoderma 167, 118-124 (2011)

12. Pan, L.: Development of soil organic matter fast determination instrument based on spectroscopy. China Agricultural University (2007)

13. Li, M.Z., Pan, L., Zheng, L.H., An, X.F.: Development of a portable SOM detector based on NIR diffuse reflection. Spectroscopy and Spectral Analysis 30(4), 1146-1150 (2010)

14. Li, M.Z., Han, D.H., Wang, X.: Spectral analysis and application. Science Press, Beijing (2006)

15. Chen, H.H., Li, X., Ding, W.X.: Twelve Kinds of Gridding Methods of Surfer 8.0 in Isoline Drawing. Chinese Journal of Engineering Geophysics 4(1), 52-57 (2007)

16. Li, X.Y., Xiao, W., Li, P.W.: Near-infrared spectral detection of soil moisture based on feature extraction of FFT. Transaction of the Chinese Society for Agricultural Machinery 40(5), 64-67 (2009)

17. Liang, X.Y., Li, X.Y.: The Research on Sample Temperature Compensation for Soil Moisture Content Based on Multi-Wavelength and LS-SVM. Chinese Journal of Sensors and Actuators 24(8), 1228-1232 (2011) 
18. Krapez, J.-C., Olioso: A combination of temperature, vegetation indexes and albedo, as obtained by airborne hyperspectral remote sensing, for the evaluation of soil moisture. Qirt Journal 8(2), 187-200 (2011)

19. Song, T., Bao, Y.D., He, Y.: Research on the Method for Rapid Detection of Soil Moisture Content Using Spectral Data. Spectroscopy and Spectral Analysis 29(3), 675-677 (2009) 